JRRD - ing

\title{
Cosmetic effect of knee joint in a knee disarticulation prosthesis
}

\author{
Fred A. de Laat, MD, PhD; ${ }^{1 *}$ Mark J. van der Pluijm, CPO; ${ }^{2}$ Annette A. van Kuijk, MD, PhD; ${ }^{3}$ Jan H. Geertzen, \\ MD, PhD; ${ }^{4}$ Leo D. Roorda, MD, PT, PhD ${ }^{5}$ \\ ${ }^{1}$ Rehabilitation Center Leijpark, Libra Rehabilitation Medicine and Audiology, Tilburg, the Netherlands; ${ }^{2}$ OIM Orthopedic \\ Services, Amsterdam, the Netherlands; and Department of Orthopedic Engineering, Fontys University of Applied Sciences, \\ University of Allied Health Professions, Eindhoven, the Netherlands; ${ }^{3}$ Rehabilitation Center Blixembosch, Libra Rehabili- \\ tation Medicine and Audiology, Eindhoven, the Netherlands; ${ }^{4}$ Department of Rehabilitation Medicine, University Medical \\ Center Groningen, University of Groningen, Groningen, the Netherlands; ${ }^{5}$ Amsterdam Rehabilitation Research Center, \\ Reade, Amsterdam, the Netherlands
}

\begin{abstract}
Despite numerous advantages, knee disarticulations (KDs) are rarely performed because of the anticipated $\mathrm{KD}$ prosthesis fitting problems that include the positioning of the knee joint distally from the KD socket. This results in lengthening of the thigh and subsequent shortening of the shank. The objective of this study was to assess the cosmetic effect of the knee joint in a KD prosthesis by determining the extent of the lengthening of the thigh and the shortening of the shank. This lengthening and shortening were measured through an experimental setup using laser techniques. These measurements were made of 18 knee joints used in KD prostheses. Lengthening of the thigh varied between 23 and $92 \mathrm{~mm}$, and shortening of the shank varied between 3 and $50 \mathrm{~mm}$. The polycentric knees Medi KH6 and Medi KHF1 showed the least lengthening of the thigh, and the polycentric knees Teh Lin Prosthetic \& Orthotic Co. Ltd Graph-Lite and Medi KP5 showed the least shortening of the shank.
\end{abstract}

Key words: amputation, cosmetic appearance, knee disarticulation, lengthening of thigh, prosthesis, prosthetic design, prosthetic knee joint, shortening of shank, sitting comfort, through-knee amputation.

\section{INTRODUCTION}

If lower-limb amputation is necessary and transtibial amputation is not feasible, knee disarticulation (KD) is the primary alternative [1-2]. Compared with transfemoral (TF) amputation, KD has many advantages, such as (1) a relatively simple operation technique with less surgical blood loss [3-4]; (2) high resistance to infection after the amputation, because the cartilage barrier is maintained [4]; (3) preservation of all thigh muscles, including the adductors, after the amputation, resulting in a more bulbous residual limb and less risk for abduction contracture; (4) a longer lever arm with less lateral displacement of the femur during weight bearing, resulting in a better fitting socket of the KD prosthesis; and, most important, (5) a fully end-bearing residual limb, so the socket of the prosthesis does not need ischial weight bearing or belts, facilitating donning and doffing. Moreover, the metabolic cost of walking with a KD prosthesis is substantially less than walking with a prosthesis after a TF amputation [1,4]. Despite all these advantages, most surgeons rarely perform KD. This aversion is due to their

\footnotetext{
Abbreviations: $\mathrm{AAK}=$ autoadaptive knee, $\mathrm{CoR}=$ center of rotation, $\mathrm{KD}=$ knee disarticulation, $\mathrm{TF}=$ transfemoral.

* Address all correspondence to Fred A. de Laat, MD, PhD; Rehabilitation Center Leijpark, PO Box 5022, 5004 EA Tilburg, the Netherlands; + 31-883133394; fax: +31-883133312. Email: f.delaat@libranet.nl http://dx.doi.org/10.1682/JRRD.2014.03.0068
} 
lack of experience with the surgical procedure and their fear for wound complications [5-7], although recent studies refute these considerations [2,7-8]. Moreover, because of the bulbous end of the residual limb and the lack of space for a knee joint, surgeons are aware of KD prosthesis fitting problems [7,9-10].

The knee joint is positioned distally from the KD socket. This results in lengthening of the thigh. Previously, lengthening of the thigh was considered to be $30 \mathrm{~mm}$ [11] or even more [6]. Due to the lengthening of the thigh, sitting in narrow spaces can be uncomfortable and getting into a car can be difficult. Moreover, especially during sitting, lengthening of the thigh has a negative influence on cosmetic appearance [1].

The lengthening of the thigh can be defined as additional thigh length composed of the (1) thickness of both the inner and the rigid outer socket, (2) thickness of the anchor of the knee joint (the connector between the socket and the knee joint), and (3) horizontal space of the knee joint in $90^{\circ}$ flexion of the knee. In the Netherlands, the inner socket is usually made of polyform (Pedilin ${ }^{\circledR}$, Otto Bock HealthCare GmbH; Duderstadt, Germany), with an average thickness of $5 \mathrm{~mm}$. If a liner is used instead, the thickness varies between 3 and $7 \mathrm{~mm}$. The rigid weight-bearing outer socket is made of laminated resin. The thickness of the outer socket depends on the body weight of the patient and the skill and experience of the manufacturer. In general, its thickness varies between 3 and $8 \mathrm{~mm}$. As a result, the inner and outer sockets add an average of 6 to $15 \mathrm{~mm}$ in addition to the lengthening effect of the knee joint and the knee anchor.

Several attempts have been made to reduce lengthening of the thigh by the knee joint. The first KD knee joints were external hinges. These joints lacked swing-phase control, were cosmetically unacceptable, and damaged overlying clothing [6]. A second way to reduce lengthening of the thigh is with a knee joint that folds back under the thigh during sitting. This is possible if, like the former (physiological) condylar knees, the center of rotation (CoR) is in line with the femoral condyles. An example of such a knee joint is the RIM-knee, especially developed for cosmetic appearance during sitting [12-13]. The RIM-knee consisted of a circular-shaped socket adaptor connected to the inner socket and a traveler sliding along the socket adaptor (Figure 1). The shear and tear forces on the surfaces of the socket adaptor were, however, substantial and resulted in premature wear to this particular knee joint. Moreover, a substantial amount of time (twice as long as other knee

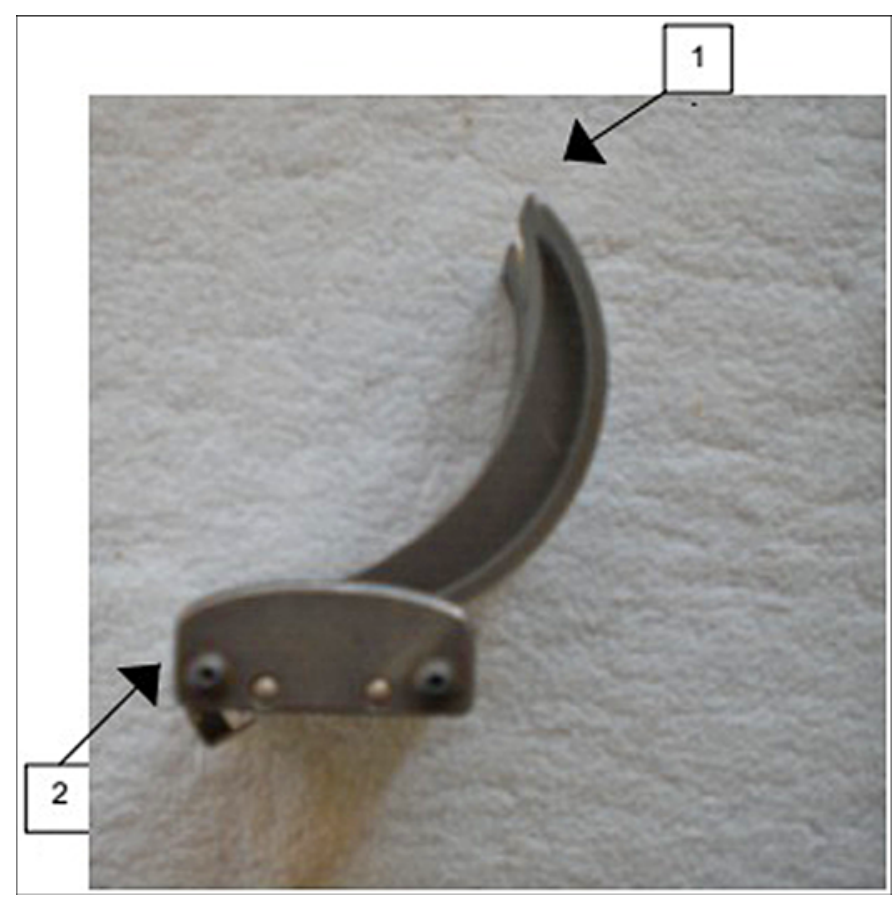

Figure 1.

RIM-knee with (1) circular-shaped socket adapter (to be connected to inner socket) and (2) traveler (sliding along socket adaptor, to be connected to shank).

joints) and expertise (specific lamination technique to connect the socket adaptor to the inner socket) were needed to build this prosthesis [14]. As a result, this knee joint, like other condylar knee joints, is no longer commercially available. A third possibility is to place a single-axis knee under the thigh, like the UFITT knee (not commercially available) [15]. This knee joint was positioned $45^{\circ}$ posterior and distal to the former anatomical CoR of the knee. For stability, this knee joint was stabilized by a block mechanism during full knee extension in the stance phase. The blockage was released by lifting the prosthesis and applying an extension moment of $0.2 \mathrm{Nm} / \mathrm{kg}$. Unfortunately, this joint has never been extensively tested in patients or commercially produced.

Nowadays, there are polycentric knee joints, designed with long anterior and posterior linkages that allow the posterior shin to tuck around the distal femur when the knee is flexed [16-17]. Some are specially designed for KD prostheses, like the Otto Bock 3R21 ${ }^{\circledR}$ and the Endolite KX06 ${ }^{\circledR}$ (Miamisburg, Ohio). However, most of the polycentric knee joints are not specially designed for KD prostheses. To use these polycentric knee joints for KD prostheses, special 
$\mathrm{KD}$ anchors are designed to lengthen the thigh as little as possible. These special anchors can be divided into two groups. The first group are those that are fixed in the proximal part of the knee joint and not fixed above the knee joint. The anchor is fixed by casting the wires of the anchor (Medi ${ }^{\circledR}$ anchor; Bayreuth, Germany) or the three arms of the anchor (Teh Lin Prosthetic \& Orthotic Co. Ltd GraphLite ${ }^{\circledR}$; New Taipei City, Taiwan) in the rigid outer socket. The second group of KD anchors, such as the Otto Bock lamination anchor, is characterized by the design of a spoon-like lamination anchor fixed at the knee joint by clamping and laminated posterior and distal in the outer socket, so the space under the knee is smaller than when using a standard knee anchor.

The shortening of the shank results from the compensation of the thickness of the inner and outer socket, the anchor, and the distance of the (instantaneous) CoR of the knee joint from the anchor. The latter is necessary because otherwise the prosthesis will be too long in a standing position [18]. In polycentric knees, the geometry of the knee joint also plays a role and is dependent on the instantaneous CoR in $90^{\circ}$ knee flexion [19]. A posteriorly located CoR will create lengthening of the shank, whereas an anteriorly or proximally located CoR will create (further) shortening of the shank [20]. Due to shortening of the shank, the foot will be lifted off the floor during sitting, which is uncomfortable for the patient $[11,21]$.

The extent of lengthening of the thigh and shortening of the shank due to knee joints and their anchors differs between different types of commercially available KD knee joints, and the exact extent of lengthening and shortening created by these joints has not been assessed systematically. The aim of this study was to determine these quanta for $18 \mathrm{KD}$ prosthetic knees currently prescribed in patients with a KD in the Netherlands.

\section{METHODS}

\section{Knee Joints}

Nowadays, the selection of a knee joint in a KD prosthesis is based primarily on stability control during standing and walking and secondarily on cosmetic aspects [22]. As a result, autoadaptive knees (AAKs), originally developed for TF amputations, and polycentric knees are most frequently prescribed. In this study, we assessed 18 knee joints most used in the Netherlands: 13 polycentric knees, of which
2 were specially designed for KD prostheses; 3 AAKs; and 2 non-AAK single-axis knees, originally designed for TF amputations. For comparison, we also assessed a condylar knee joint (RIM-knee, Figure 1). The knee joints tested are listed in the Table.

\section{Assumptions for Experimental Setup}

The following assumptions have been made:

1. The anchor of the KD knee is the most proximal part of the knee joint and is located at the most distal part of the outer socket, covering the residual limb.

2. In a sitting position, the knee axis of the KD prosthesis is in $90^{\circ}$ flexion.

Considering the distal end of the residual limb as a segment of a cone, the distal end of the socket and its (laminated) anchor can be considered a circle. To determine the most distal part of the outer socket, a sagittal line was drawn at the proximal side of the most distal part of the anchor of the prosthetic knee joint. This line was supposed to be horizontal. Second, a vertical line was projected perpendicular to this sagittal line exactly in the middle of the anchor. The point at which these two lines intersected was considered the most distal part of the outer socket (Figure 2): the reference point. The Otto Bock knee anchor (Figure 2(d)) and the RIM-knee (Figure 2(e)) have a somewhat different construction. They fit only the dorsal part of the socket and end distally at the middle half of the socket. These anchors are horizontal at their most distal parts. As a result, the vertical line intersects the horizontal line at the ventral side of these anchors.

\section{Procedure}

The experimental setup is shown in Figure 3. A prosthetic knee positioning apparatus was custom made. The positioning apparatus consisted of a tube with a diameter of $30 \mathrm{~mm}$ and length of $225 \mathrm{~mm}$ connected to a metal plate by a (male) pyramid adapter. The tested knee joints were connected to the prosthetic knee positioning apparatus. In every KD knee joint, the knee anchor recommended by the manufacturer of the knee joint was used. The knee joints were mounted to and aligned with the prosthetic knee positioning apparatus using the adapter recommended by the manufacturer.

Next, the prosthetic knee positioning apparatus with the tested knee joint including the knee anchor was secured vertically onto a table. A technical sign plate (i.e., a perfectly flat plate provided with a ruler) was positioned 
JRRD, Volume 51, Number 10, 2014

Table.

Knee joints: Lengthening of thigh and shortening of shank.

\begin{tabular}{lcc}
\hline \multicolumn{1}{c}{ Type of Knee Joint } & Thigh Lengthening (mm) & Shank Shortening (mm) \\
\hline Condylar Knee, Designed for KD & 15.0 & 0 \\
RIM-knee & & 19.0 \\
Polycentric Knee, Designed for KD & 49.0 & 15.5 \\
Endolite KX06 & 30.5 & 8.0 \\
Otto Bock 3R30 & & 10.0 \\
Polycentric TF Knee with KD Anchor & 25.0 & 18.0 \\
Medi KFM1 & 23.0 & 6.0 \\
Medi KH6 & 28.0 & 30.5 \\
Medi KHP3 & 43.0 & 12.0 \\
Medi KP5 & 58.5 & 3.0 \\
Otto Bock 3R60 & 59.0 & 17.0 \\
Otto Bock 3R106 & 57.0 & 10.0 \\
Teh Lin Prosthetic \& Orthotic Co. Ltd Graph-Lite & & 10.5 \\
Polycentric TF Knee Without KD Anchor & 70.0 & 9.0 \\
Uniprox JT20 & 49.0 & \\
Nabtesco NK-6 SH & 37.0 & 47.0 \\
Ossur Total Knee 2000 & 41.0 & 48.0 \\
Ossur Total Knee 2100 & & 32.5 \\
TF AAK Knee + Single Axis Without KD Anchor & 91.0 & 28.0 \\
Endolite ESK4B IP & 92.5 & 50.0 \\
Ossur Rheo Knee & 72.0 & 71.0 \\
Otto Bock C-leg & 87.0 & \\
Ossur Mauch Knee & & \\
Ultimate Knee & & \\
Not & & \\
\hline
\end{tabular}

Note: Otto Bock 3R30 has same technical structure as Otto Bock 3R21, 3R23, 3R32, and 3R46. Ossur Total Knee 2000 has same technical structure as Ossur Total Knee 1900. Medi KH6 has same technical structure as Medi KH5.

AAK = autoadaptive knee, $\mathrm{KD}=$ knee disarticulation, $\mathrm{TF}=$ transfemoral.

parallel to the prosthetic knee positioning apparatus. A laser joint (Laserline ${ }^{\circledR}$, Otto Bock) was positioned parallel to both the prosthetic knee positioning apparatus and the sign plate (Figure 3(a)). The laser beam was positioned perpendicular to the sign plate and aimed at the reference point indicating the most distal part of the outer socket (Figure 3(b)).

\section{Measurements}

In patients, the lengthening of the thigh is considered the horizontal distance between the most distal part of the residual limb and the most distal upper part of the prosthetic knee (Figure 4). The amount of lengthening of the thigh section due to the prosthetic knee and its laminated knee anchor during sitting is caused by the length between the distal end of the outer socket and the most distal prominent part of the knee joint. To determine the lengthening effect of the knee joint and anchor, we positioned the knee joint in $90^{\circ}$ flexion. In this position, the laser beam was aimed first at the reference point and second at the most prominent part of the knee joint. As such, it includes both the knee joint and its anchor (Figure 4). Both projections were marked on the sign plate. The amount of lengthening of the thigh section due to the knee joint was considered the horizontal distance between the two projections.

The shortening of the shank during sitting is considered the vertical distance the foot traveled up when the (prosthetic) knee was in $90^{\circ}$ flexion, assuming that the thigh section does not change position. However, to determine the shortening effect of the knee joint and its anchor, measuring the vertical distance of the foot above the floor is inappropriate because, in that case, the shortening effect for the compensation of the thickness of the inner and outer socket is included as well. Therefore, we used an 

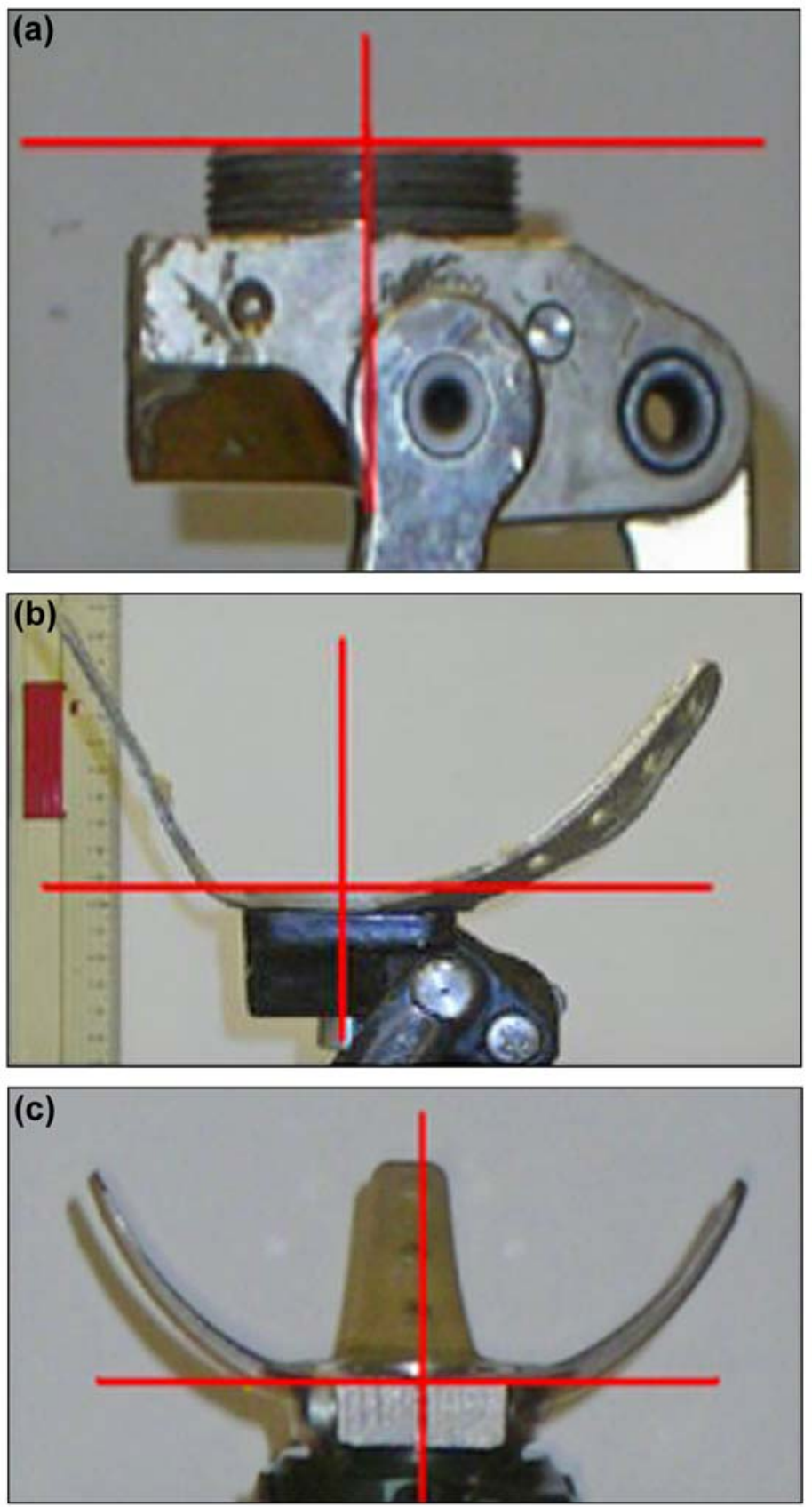
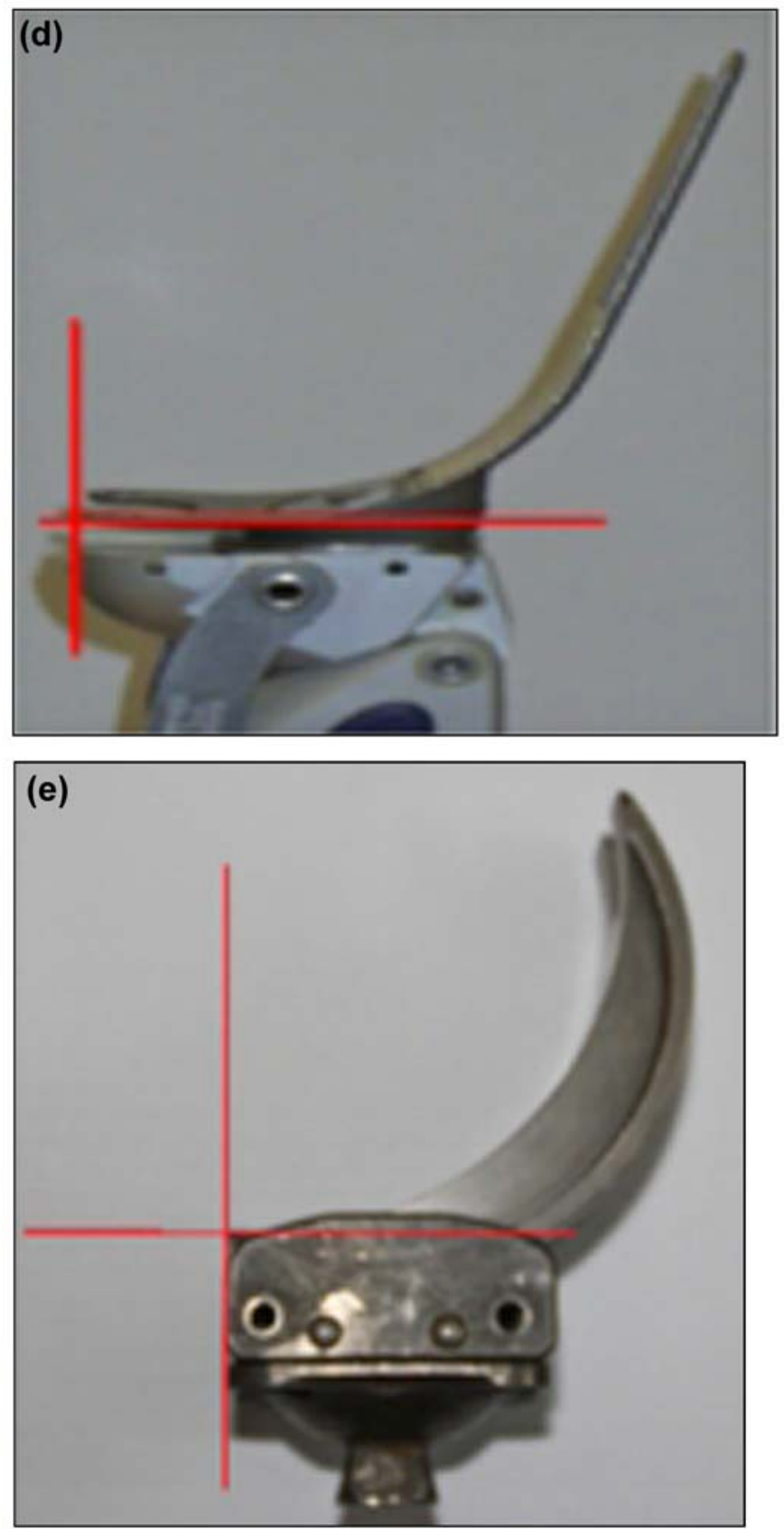

Figure 2.

Reference points reflecting distal part of outer socket. (a) Ossur Rheo knee; Otto Bock C-leg; Endolite KX06; Medi knee KFM1, KH6, KHP3, and KP5; and Ossur Total Knee 2000 and 2100. Anchor is as thick as screw connector and screwed onto it. (b) Teh Lin Prosthetic \& Orthotic Co. Ltd Graph-Lite. (c) Endolite ESK4B IP, Ossur Mauch knee, Ultimate Knee, Uniprox JT20, and Nabtesco NK-6 SH. (d) Otto Bock 3R30, 3R60, and 3R106. (e) RIM-knee.

indirect measurement. Instead of measuring the elevation of the (prosthetic) foot, we wanted to know (in theory) how much the seating had to be lowered to place the pros- thetic foot on the floor. Therefore, we fixated the distal point of the knee mechanism and measured the vertical position of the reference point in both knee extension and 

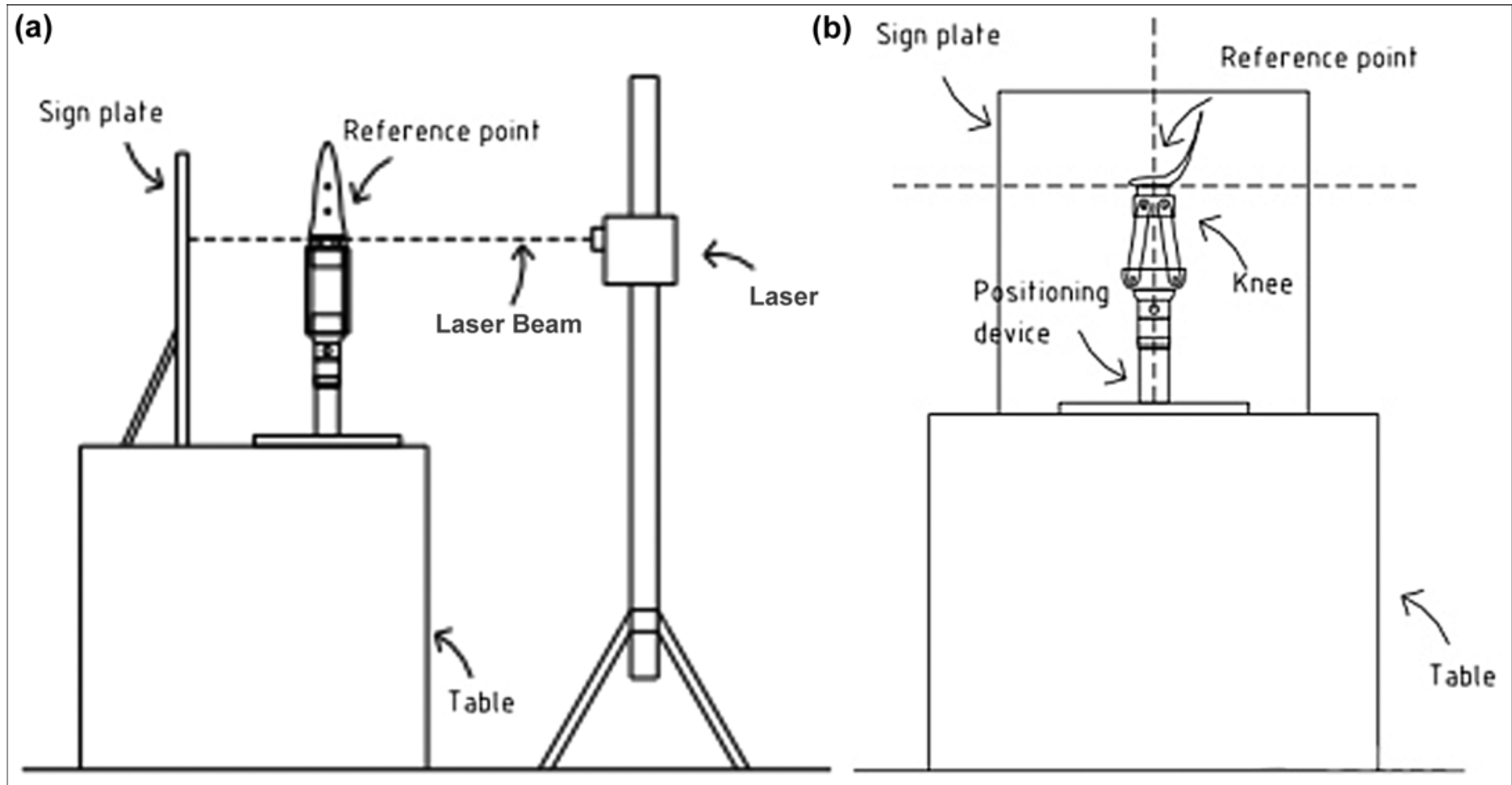

Figure 3.

Experimental setup. (a) Sagittal view and (b) frontal view.

in $90^{\circ}$ flexion by using a laser beam aimed at the reference point. As such, the difference in vertical positions of the reference point during knee extension and in $90^{\circ}$ flexion of the knee joint represents the shortening of the shank (Figure 5).

All measurements were performed twice by the same experimenter (M. J. P.). The mean of these two measurements was calculated and intraobserver differences were calculated. To visualize both quanta together, the data were presented in a scatter plot.

\section{RESULTS}

The intraobserver differences between the two measurements were less than $1 \mathrm{~mm}$. The results with respect to lengthening of the thigh are presented in the Table and visualized in a scatter plot (Figure 6).

The lengthening of the thigh due to the knee joint and the laminated anchor ranged between 23 and $92 \mathrm{~mm}$. The AAKs and the single-axis knees showed more lengthening than the polycentric knees. In five knee joints (the Medi $\mathrm{KFM}^{\circledR}{ }^{\circledR}$, Medi KH6 ${ }^{\circledR}$, Medi KHP3 ${ }^{\circledR}$ [polycentric knee joints with special KD anchor], Otto Bock $3 R 30^{\circledR}[\mathrm{KD}$ knee joint with special KD anchor], and Ossur Total Knee $2000^{\circledR}$ [polycentric knee joint with regular anchor]), lengthening of the thigh was less than $40 \mathrm{~mm}$. The no longer available RIM-knee showed the least lengthening of the thigh $(15 \mathrm{~mm})$.

The shortening of the shank ranged between 3 and $50 \mathrm{~mm}$. In four knee joints (the Medi KFM1, Medi KP5, Teh Lin Prosthetic \& Orthotic Co. Ltd Graph-Lite ${ }^{\circledR}$ [polycentric knee joints with special KD anchor], and Ossur Total Knee $2100^{\circledR}$ [polycentric knee joint with regular anchor]), the shortening of the shank section was less than $10 \mathrm{~mm}$. The no longer available RIM-knee had no shortening effect at all.

\section{DISCUSSION AND STUDY LIMITATIONS}

In a $\mathrm{KD}$ prosthesis, the lengthening of the thigh and consequent shortening of the shank are related to the design characteristics of the knee joint. The selection of a knee joint for patients with $\mathrm{KD}$ is primarily based on 


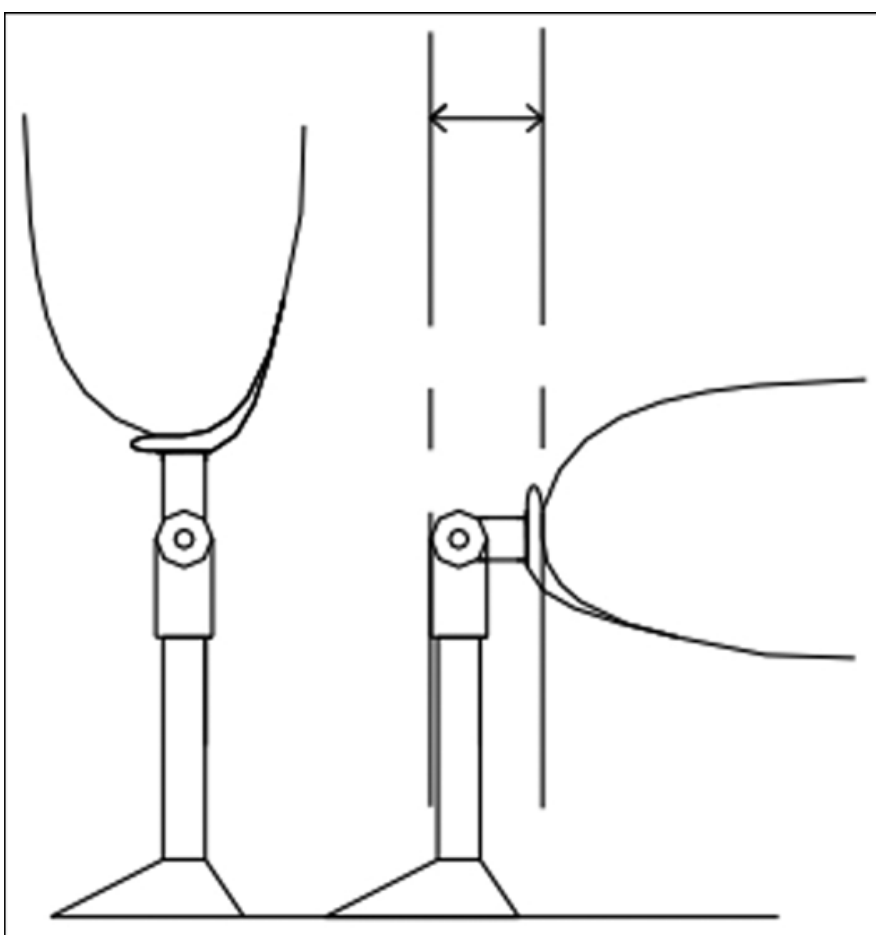

Figure 4.

Lateral view of lengthening of thigh during sitting.

stability control during standing and walking and secondarily on cosmetic aspects [22]. The exact extent of lengthening of the thigh and shortening of the shank in different types of knee joints and their anchors is, however, not known. In this study, an experimental setup was created to determine these characteristics in 18 commercially available KD knee joints and in a condylar knee joint constructed especially for cosmetic purposes (RIM-knee).

The lengthening of the thigh section due to the knee joint and its laminated anchor was substantial (23-92 mm). These results are in-line with a previous study [11]. The AAKs and the single-axis knees showed more lengthening than the polycentric knees. In only five knee joints (the Medi KFM1, Medi KH6, Medi KHP3, Otto Bock 3R30, and Ossur Total Knee 2000) was lengthening of the thigh less than $40 \mathrm{~mm}$. Aside from the Total Knee 2000, all these polycentric knee joints have a special KD anchor. So, in clinical practice, if cosmetic appearance and comfort during sitting are (the only) variables involved in choosing a prosthetic knee joint, these five knee joints should be preferred. The no longer available RIM-knee, however, showed the least lengthening of the thigh $(15 \mathrm{~mm})$.

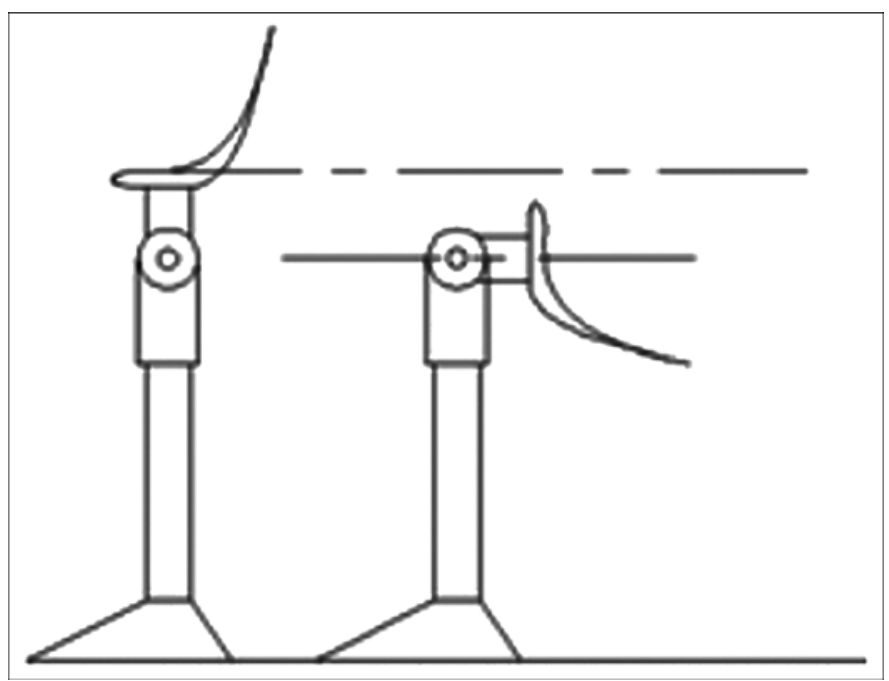

Figure 5.

Lateral view of shortening of shank during sitting with knee in $90^{\circ}$ flexion. Foot is held in fixed position.

The shortening of the shank section due to the knee joint and its anchor varied substantially (3-50 mm). In only four knee joints (the Medi KFM1, Medi KP5, Ossur Total Knee 2100, and Teh Lin Prosthetic \& Orthotic Co. Ltd Graph-Lite) was shortening of the shank section less than $10 \mathrm{~mm}$. Aside from the Total Knee 2100, all these polycentric knee joints have a special KD anchor. The RIM-knee had no shortening effect at all, due to its CoR being in-line with the femoral condyles. So, from a cosmetic viewpoint this RIM-knee should be reconsidered as an alternative to the polycentric knees tested in this study, especially when, in the future, concerns about the high shear and tear forces on the surfaces of the socket adaptor of this knee, which result in premature wear, can be overcome.

We only studied the effect of the knee joint and its anchor on the lengthening of the thigh and the shortening of the shank. The thickness of the (inner and outer) socket is also, however, responsible for a considerable amount of the lengthening of the thigh and shortening of the shank. If a cosmetic cover, usually made of polyurethane foam, is used as well, cosmetic appearance of the prosthetic limb during sitting will be even worse. Future development in socket materials, as well as standardization of socket production processes, might reduce this lengthening of the KD prosthesis. 
JRRD, Volume 51, Number 10, 2014

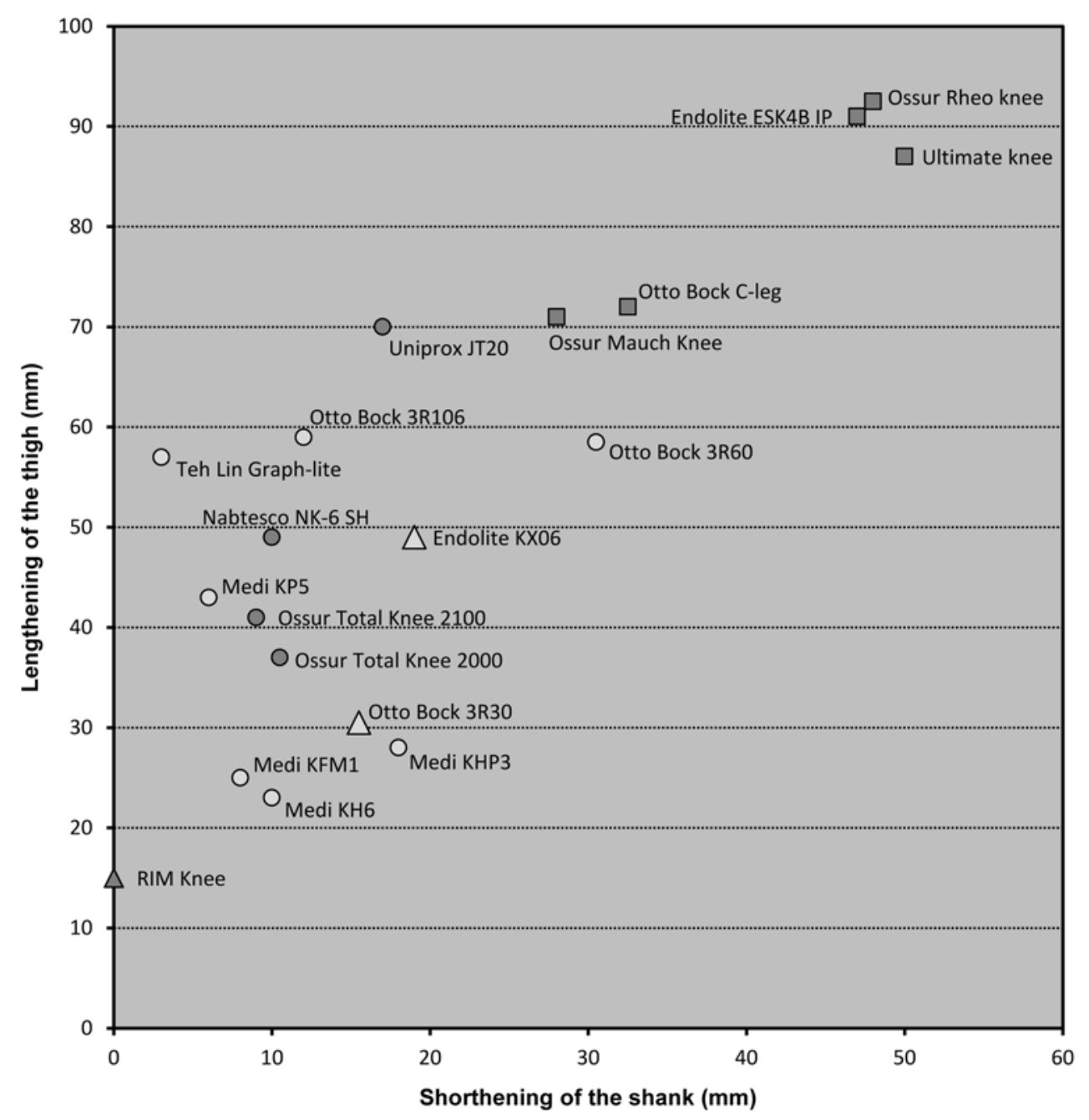

$\Delta$ condylar knee designed for KD

$\Delta$ polycentric knee designed for KD

O polycentric TF knee with KD anchor

O polycentric TF knee without KD anchor

口TF AAK knee+ single axis without KD anchor

\section{Figure 6.}

Scatterplot of lengthening of thigh and shortening of shank in knee joints used in knee disarticulation (KD) prostheses. AAK = autoadaptive knee, TF = transfemoral.

\section{CONCLUSIONS}

In a KD prosthesis, the lengthening of the thigh and consequent shortening of the shank are related to the design characteristics of the knee joint. An experimental setup was used to assess the lengthening of the thigh section and the shortening of the shank section in $18 \mathrm{KD}$ knee joints and their anchors. Due to their extended lengthening of the thigh, single-axis knees, including AAKs, had a less favorable cosmetic appearance during sitting than the polycentric knees. If comfort and cosmetic appearance in a sitting position are the most important characteristics to the patient, the Medi KFM1 and Medi KH6 joints have the best outcome. With a global $25 \mathrm{~mm}$ lengthening of the thigh and $10 \mathrm{~mm}$ shortening of the shank, the cosmetic argument for avoiding KDs is no longer valid.

\section{ACKNOWLEDGMENTS}

\section{Author Contributions:}

Study concept and design: F. A. de Laat, M. J. van der Pluijm. Acquisition of data: M. J. van der Pluijm.

Drafting of manuscript: F. A. de Laat.

Critical revision of manuscript for important intellectual content:

F. A. de Laat, M. J. van der Pluijm, A. A. van Kuijk, J. H. Geertzen, L. D. Roorda.

Clinical review: F. A. de Laat, A. A. van Kuijk, J. H. Geertzen, L. D. Roorda. 
Financial Disclosures: The authors have declared that no competing interests exist.

Funding/Support: This material was unfunded at the time of manuscript preparation.

\section{REFERENCES}

1. Hagberg E, Berlin OK, Renström P. Function after throughknee compared with below-knee and above-knee amputation. Prosthet Orthot Int. 1992;16(3):168-73. [PMID:1491950]

2. Ten Duis K, Bosmans JC, Voesten HG, Geertzen JH, Dijkstra PU. Knee disarticulation: Survival, wound healing and ambulation. A historic cohort study. Prosthet Orthot Int. 2009;33(1):52-60. [PMID:19235066]

http://dx.doi.org/10.1080/03093640802557020

3. Baumgartner RF. Knee disarticulation versus above-knee amputation. Prosthet Orthot Int. 1979;3(1):15-19. [PMID:471700]

4. Pinzur MS. Gait analysis in peripheral vascular insufficiency through-knee amputation. J Rehabil Res Dev. 1993;30(4):388-92. [PMID:8158554]

5. Batch JW, Spittler AW, McFaddin JG. Advantages of the knee disarticulation over amputations through the thigh. J Bone Joint Surg Am. 1954;36-A(5):921-30. [PMID:13211689]

6. Michael JW. Knee disarticulation/prosthetic management. In: Bowker HK, Michael JW, editors. Atlas of limb prosthetics: Surgical, prosthetic, and rehabilitation principles. 2nd ed. St. Louis (MO): Mosby-Year Book; 1992.

7. Morse BC, Cull DL, Kalbaugh C, Cass AL, Taylor SM. Through-knee amputation in patients with peripheral arterial disease: A review of 50 cases. J Vasc Surg. 2008;48(3): 638-43, discussion 643. [PMID:18586441] http://dx.doi.org/10.1016/j.jvs.2008.04.018

8. Bowker JH, San Giovanni TP, Pinzur MS. North American experience with knee disarticulation with use of a posterior myofasciocutaneous flap. Healing rate and functional results in seventy-seven patients. J Bone Joint Surg Am. 2000;82-A(11):1571-74. [PMID:11097446]

9. Fyfe NC. An audit of amputation levels in patients referred for prosthetic rehabilitation. Prosthet Orthot Int. 1990; 14(2):67-70. [PMID:2235302]

10. Moran BJ, Buttenshaw P, Mulcahy M, Robinson KP. Through-knee amputation in high-risk patients with vascular disease: Indications, complications and rehabilitation. Br J Surg. 1990;77(10):1118-20. [PMID:2224460] http://dx.doi.org/10.1002/bjs.1800771014

11. Oberg K. Knee mechanisms for through-knee prostheses. Prosthet Orthot Int. 1983;7(2):107-12. [PMID:6622228]
12. de Vetten AL. [Exarticulation in the knee and a new prosthetic knee joint]. Ned Tijdschr Geneeskd. 1975;119(34): 1304-6. Dutch. [PMID:1165801]

13. Neff G. Knee-disarticulation. Acta Chir Belg. 1981;80(5): 253-61. [PMID:7304052]

14. Knoche W. [New manufacturing procedures for the knee disarticulation prosthesis demonstrated on the improved RIM Knee]. Orthopaedie-Technik. 1981;32:93-95. German.

15. Lemmers LG. The UFITT prosthesis: An open throughknee prosthesis with adjustable stabilisation [dissertation]. [Enschede, the Netherlands]: University of Twente; 1994.

16. Stark G. Overview of knee disarticulation. J Prosthet Orthot. 2004;16:130-37. http://dx.doi.org/10.1097/00008526-200410000-00007

17. Gard SA, Childress DS, Uellendahl JE. The influence of four-bar linkage knees on prosthetic swing-phase foot clearance. J Prosthet Orthot. 1996;8:34-40. http://dx.doi.org/10.1097/00008526-199600820-00004

18. Nelson VS, Flood KM, Bryant PR, Huang ME, Pasquina PF, Roberts TL. Limb deficiency and prosthetic management. 1. Decision making in prosthetic prescription and management. Arch Phys Med Rehabil. 2006;87(3 Suppl 1):S3-9. [PMID:16500187] http://dx.doi.org/10.1016/j.apmr.2005.11.022

19. Greene MP. Four bar linkage knee analysis. Orthot Prosthet. 1983;37:15-24.

20. van der Veen PG. [Functional properties of polycentric knee joints]. Med Orth Tech. 2000;122:125-34. German.

21. Michael JW. Component selection criteria. Lower limb disarticulations. Clin Prosthet Orthot. 1988;12(3):99-108.

22. Van Der Linde H, Geertzen JH, Hofstad CJ, Van Limbeek J, Postema K. Prosthetic prescription in the Netherlands: An interview with clinical experts. Prosthet Orthot Int. 2004;28(2):98-104. [PMID:15382803] http://dx.doi.org/10.1080/03093640408726694

Submitted for publication March 5, 2014. Accepted in revised form August 29, 2014.

This article and any supplementary material should be cited as follows:

de Laat FA, van der Pluijm MJ, van Kuijk AA, Geertzen $\mathrm{JH}$, Roorda LD. Cosmetic effect of knee joint in a knee disarticulation prosthesis. J Rehabil Res Dev. 2014;51(10): 1545-54.

http://dx.doi.org/10.1682/JRRD.2014.03.0068

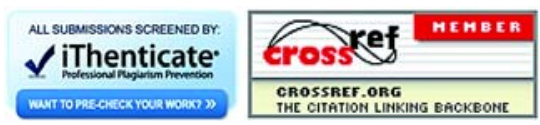


